\title{
Determination of IgA- and IgM-rheumatoid factors in patients with rheumatoid arthritis with and without nephropathy
}

Masaaki Nakano, Mitsuhiro Ueno, Shinichi Nishi, Satoru Suzuki, Hisashi Hasegawa,
Takeshi Watanabe, Takeshi Kuroda, Satoshi Ito, Masaaki Arakawa

Abstract

Objective-To clarify the characteristics and pathogenesis of renal disorders in patients with rheumatoid arthritis (RA). Methods-In this study, 143 patients with RA were included, from whom 43 with urinary abnormalities were biopsied. Serum rheumatoid factor (RF) concentrations of $\operatorname{IgA}$ and $\operatorname{Ig} M$ isotypes were also measured in these patients by enzyme linked immunosorbent assay.

Results-Light microscopy of renal biopsy specimens showed minor glomerular abnormalities in six patients, mesangial proliferative glomerulonephritis (GN) in 21, membranous nephropathy in seven, renal amyloidosis in seven, and tubulointerstitial nephritis in two. Twelve patients with mesangial proliferative GN and one with minor glomerular abnormalities were found by immunofluorescence microscopy to have abnormalities consistent with IgA GN. Although the concentrations of IgA-RF in patients with IgA GN were slightly raised compared with those with glomerulopathy established by biopsy but not associated with IgA GN, the concentrations of IgARF were higher in patients with $R A$ with vasculitis or interstitial pneumonia than those with RA complicated by IgA GN. Conclusions-Mesangial proliferative GN, including IgA GN, may be a frequent renal lesion in Japanese patients with RA. IgA-RF may play little pathogenetic part in the development of IgA GN in RA.

(Ann Rheum Dis 1996; 55: 520-524)

Department of

Medicine (II),

Niigata University

School of Medicine,

Niigata, Japan

M Nakano

$M$ Ueno

S Nishi

S Suzuki

H Hasegawa

$T$ Watanabe

T Kuroda

S Ito

M Arakawa

Correspondence to: Dr Masaaki Nakano,

Department of Medicine (II)

Niigata University School

of Medicine,

Asahimachi-Dori 1-757, Niigata 951, Japan.

Accepted for publication 11 April 1996

data from several studies have disclosed that the occurrence of isolated mesangiopathy in patients with RA is not associated with drug treatment. ${ }^{3} 1518$

On the other hand, it has been postulated that rheumatoid factor (RF) may play some pathogenetic part in the development of some types of GN. ${ }^{19-22}$ More recently, immunological comparison of patients with RA with various forms of nephropathy with those without clinical renal disease showed no difference in RF and immune complex determinations. ${ }^{23}$

We studied the renal lesions of 43 patients with RA and urinary abnormalities by light, electron, and immunofluorescence microscopy. Concentrations of IgA and IgM isotype RF were also measured in serum samples from these patients to investigate the relation between class specific RFs and renal lesions such as IgA GN.

\section{Patients and methods}

PATIENTS

Patients admitted to our clinic from 1979 to 1995 were included in the study. There were 143 patients, 38 men and 105 women, mean age at admission 55.4 (SD 12.6) years (range $20-84)$. The mean duration of RA before admission was $10.3(8.7)$ years (range 6 months-53 years). All patients satisfied the 1987 revised criteria of the American College of Rheumatology for RA. ${ }^{24}$ Patients with RA who also had systemic lupus erythematosus, mixed connective tissue disease, or progressive systemic sclerosis were excluded from the study.

The radiological progression of $\mathrm{RA}$ was determined as advocated by Steinbrocker et $a l .{ }^{25}$ The antirheumatic drugs used before the renal biopsy were surveyed retrospectively from the hospital charts. Intravenous urograms were performed in all biopsied patients and no serious urological abnormalities were detected. Urinary tract infection was ruled out by culture of midstream urine. inflammatory drugs (NSAIDs), including interstitial nephritis, papillary necrosis, and nephrotic syndrome. ${ }^{9-13}$

Although glomerulonephritis (GN) had been thought to be rare in patients with $R A,{ }^{14}$ mesangial proliferative lesions have been recognised to be the most dominant glomerular abnormality as determined by light, electron, and immunofluorescence microscopy in recent studies. ${ }^{315-17}$ Accumulated clinical

Renal biopsy was performed because of clinica or laboratory evidence of renal disease, after obtaining each patient's informed consent. Histological evaluations were performed by light, electron, and immunofluorescence microscopy. Light microscopic evaluation was 
done after staining with haematoxylin and eosin, periodic acid Schiff, periodic acid methonamine silver (PAM), PAM Masson, elastica Masson, and Congo red. Immunofluorescence studies were performed on cryostat sections using fluorescein isothiocyanate conjugated antisera to human immunoglobulins (IgG IgA, and IgM), complement (C3, C4, and $\mathrm{Clq}$ ), and fibrinogen. In patients with renal amyloidosis, the potassium permanganate reaction was used to distinguish between primary and secondary amyloidosis. The presence of characteristic non-branching fibrils on electron microscopy confirmed the diagnosis of renal amyloidosis.

RENAL FUNCTION AND URINARY EXAMINATION Renal function at the time of admission was determined from serum creatinine measurements. Loss of renal function was assumed when the serum creatinine exceeded $1.2 \mathrm{mg} / \mathrm{dl}$. Haematuria was defined as $\geqslant$ five red blood cells per high power field on urinalysis. Proteinuria was defined as urinary protein excretion $\geqslant 0.3 \mathrm{~g} / 24 \mathrm{~h}$ and nephrotic range proteinuria $\geqslant 3.5 \mathrm{~g} / 24 \mathrm{~h}$.

\section{IMMUNOLOGICAL DETERMINATIONS}

Serum immunoglobulins (IgG, IgA, and IgM) and serum complement factors (C3 and C4) were measured by laser nephelometry. Conventional RF activity was determined by turbidity immunoassay (TIA-RF). TIA-RF activity was defined as abnormal when the serum concentration exceeded $10 \mathrm{IU} / \mathrm{ml}$.

MEASUREMENT OF CLASS SPECIFIC RFS

IgA-RF and IgM-RF were detected by enzyme linked immunosorbent assays (ELISA) as described by Bampton et $a l^{26}$ with minor modifications. Briefly, rabbit IgG (R-IgG) was used as antigen and R-IgG $(50 \mu \mathrm{l})$ at a concentration of $10 \mu \mathrm{g} / \mathrm{ml}$ in $50 \mathrm{mM}$ sodium carbonate buffer pH 9.6 was added to Nunc ELISA microtitre plates. Wells containing only sodium carbonate buffer $(50 \mu \mathrm{l})$ were prepared as controls. The plates were incubated overnight at $37^{\circ} \mathrm{C}$, then washed three times with Tris- $\mathrm{HCl}$ buffer $(0 \cdot 15 \mathrm{M}$ Tris, $\mathrm{pH} \mathrm{7 \cdot 6)}$ containing $0.05 \%$ Tween 20 and $0.2 \%$ gelatin (washing solution).

After IgG coating, bovine serum albumin $(20 \mathrm{mg} / \mathrm{ml})$ in washing solution was treated for two hours at room temperature to block nonspecific antibody adsorption. After washing three times, serum diluted 1:200 in washing solution was added to each well. The plates were incubated for six hours at $4^{\circ} \mathrm{C}$ and then washed three times. The peroxidase conjugated second antibody diluted 1:2000 in washing solution was added to each well and the plate incubated at $4^{\circ} \mathrm{C}$ for two hours. After washing three times with washing solution, $100 \mu \mathrm{l}$ of substrate solution (o-phenylenediamine) was added. The solution was then incubated for 20 minutes, followed by addition of $100 \mu l 1 \mathrm{~N} \mathrm{H}_{2} \mathrm{SO}_{4}$. IgA-RF and IgM-RF were measured in 61 patients and 27 normal controls.

The optical density was measured and the results were compared with the density of normal pooled sera as described by Powell et $a l^{27}$ or Gioud-Paquet et al. ${ }^{28}$ The results were expressed as:

(mean OD with $\mathrm{Ag}$ - mean OD without $\mathrm{Ag}$ )

test serum/(mean OD with $\mathrm{Ag}$ - mean OD without $\mathrm{Ag}$ ) normal pooled sera

where $\mathrm{OD}=$ optical density; $\mathrm{Ag}=$ antigen.

Mean (SD) serum IgA-RF and IgM-RF concentrations in 27 normal controls were 1.06 $(0.62)$ and $1.08(0.51)$, respectively. The upper limits of the normal range for IgA-RF and IgM-RF were defined by the mean $+2 S D$ of the normal controls as $2 \cdot 3$ and $2 \cdot 1$ respectively. The same normal pooled sera were used for all assays.

Serum samples were stored at $-70^{\circ} \mathrm{C}$ before use.

\section{STATISTICS}

Statistical analysis by Student's $t$ test and $\chi^{2}$ test was used to assess subgroup differences in age at renal biopsy, duration of RA, stage of $R A$, immunoglobulins, class specific RFs and TIA-RF, urinalysis findings, and serum creatinine.

\section{Results}

Renal biopsy was performed in 43 out of 143 patients. Table 1 shows the biopsy findings. The common nephropathy types included mesangial proliferative glomerulopathy in 21 patients, $\mathrm{MN}$, and secondary amyloidosis in seven. Twelve of 21 patients with mesangial proliferative GN and one with minor glomerular abnormalities were classified as IgA $\mathrm{GN}$, because the main glomerular immunofluorescence finding in the biopsy specimen was diffuse global IgA deposition. ${ }^{29}$ There was no significant difference between patients with mesangial proliferative $\mathrm{GN}$ and other renal histopathology groups for sex or the use of antirheumatic drugs; non-steroidal antiinflammatory drugs (NSAIDs) had been used in every patient. Three of seven patients with $R A$ with $M N$ received no antirheumatic drug at any point.

Non-renal extra-articular manifestations, including vasculitis and interstitial pneumonia, were recognised in 23 patients. The histological diagnosis of secondary amyloidosis was made from biopsies of the rectum, upper

Table 1 Renal histological classification by light microscopy

\begin{tabular}{lrrrrl}
\hline Classification & $\begin{array}{c}\text { Patients } \\
(n)\end{array}$ & $\begin{array}{l}\text { Sex } \\
M / F\end{array}$ & \multicolumn{2}{c}{ Drug history } \\
\cline { 3 - 6 } & & & Gold & $D-P C$ \\
\hline Minor glomerular abnormality & 6 & $0 / 6$ & 6 & 2 \\
Mesangial proliferative GN & 21 & $5 / 16$ & 19 & 4 \\
Amyloidosis & 7 & $0 / 7$ & 5 & 4 \\
Membranous nephropathy & 7 & $3 / 4$ & 4 & 2 \\
Tubulointerstitial nephritis & 2 & $0 / 2$ & 1 & 0 \\
No histological evaluation & 100 & $30 / 70$ & - & - \\
\hline
\end{tabular}

D-PC $=$ D-penicillamine.

Values are numbers of patients. 
gastrointestinal tract, or abdominal wall fat in 19 other patients who underwent no renal histological evaluation. Renal disorders were recognised without histological examination in 12 other patients.

According to clinical and histological findings, the patients were divided into six subgroups: (a) patients with IgA GN (IgA GN; $\mathrm{n}=13)$; (b) patients with minor glomerular abnormalities and mesangial glomerulopathy except for IgA GN (non-IgA GN; $n=14$ ); (c) patients with secondary amyloidosis (amyloidosis; $\mathrm{n}=26$ ); (d) patients with vasculitis or interstitial pneumonia (vasculitis; $\mathrm{n}=23$ ); (e) patients with $\mathrm{MN}$ (membranous) $(\mathrm{n}=7)$; $(f)$ patients without clinical renal manifestations (controls; $n=46$ ). Patients with interstitial nephritis $(n=2)$ and patients with renal disorder who underwent no histological evaluation $(n=12)$ were excluded from this study.

The vasculitis group and amyloidosis group were significantly older than the group with IgA GN but were not significantly different from the controls. The mean duration of RA, however, was significantly longer in the

Table 2 Comparison of age, duration of disease and stage of $R A$

\begin{tabular}{llll}
\hline Group $(n)$ & Age $(y)$ & Duration $(y)$ & Stage of $R A$ \\
\hline IgA GN (13) & $46 \cdot 2(9 \cdot 3)^{\star \star 1} \star \star 2$ & $11 \cdot 3(6 \cdot 5)$ & $2 \cdot 7(1 \cdot 3)^{\star \star 2}$ \\
Non-IgA GN (14) & $53 \cdot 8(13 \cdot 9)$ & $10 \cdot 2(9 \cdot 2)$ & $2 \cdot 3(1 \cdot 0)^{\star 2}$ \\
Amyloidosis (26) & $60 \cdot 0(10 \cdot 2)$ & $16 \cdot 3(11 \cdot 5)$ & $3 \cdot 8(0 \cdot 4)$ \\
Vasculitis (23) & $59 \cdot 2(7 \cdot 9)$ & $8 \cdot 4(8 \cdot 1)^{\star \star 2}$ & $2 \cdot 6(0 \cdot 8)^{\star \star 2}$ \\
Membranous (7) & $52 \cdot 3(12 \cdot 8)$ & $8 \cdot 0(5 \cdot 4)^{\star 2}$ & $2 \cdot 7(1 \cdot 1)^{\star 2}$ \\
Control (46) & $54 \cdot 7(15 \cdot 0)$ & $8 \cdot 0(6 \cdot 9)^{\star \star 2}$ & $2 \cdot 4(1 \cdot 1)^{\star \star 2}$ \\
\hline
\end{tabular}

Values are mean (SD).

${ }^{\star} \mathrm{p}<0.05,{ }^{\star \star} \mathrm{p}<0.01 ; 1=v$ vasculitis; $2=v$ amyloidosis.

Table 3 Renal presentation in various groups of patients with $R A$

\begin{tabular}{lcllc}
\hline Group (n) & $\begin{array}{c}\text { Proteinuria } \\
\geqq 0 \cdot 3 \text { g/day }\end{array}$ & $\begin{array}{l}\text { Nephrotic } \\
\text { syndrome }\end{array}$ & $\begin{array}{l}\text { Haematuria } \\
\geqq 5 R B C / h p f\end{array}$ & $\begin{array}{c}\text { Serum } C r \\
>1 \cdot 2 \mathrm{mg} / \mathrm{dl}\end{array}$ \\
\hline IgA GN (13) & 5 & 0 & 13 & 1 \\
Non-IgA GN (14) & 3 & 1 & 12 & 0 \\
Amyloidosis (26) & 21 & 7 & 13 & 19 \\
Vasculitis (23) & 0 & 0 & 3 & 0 \\
Membranous (7) & 6 & 4 & 1 & 2 \\
Control (46) & 0 & 0 & 0 & 0 \\
\hline
\end{tabular}

Values are numbers of patients.

$\mathrm{RBC}=$ red blood cells; $\mathrm{hpf}=$ high power field; $\mathrm{Cr}=$ creatinine.

Table 4 Comparison of the concentrations of immunoglobulin $G, A$, and $M$

\begin{tabular}{llll}
\hline Group $(n)$ & $I g G(m g / d l)$ & $I g A(m g / d l)$ & $I g M(m g / d l)$ \\
\hline IgA GN (13) & $1508(619)$ & $395(107)$ & $160(88)$ \\
Non-IgA GN (14) & $1536(470)^{\star}$ & $398(223)$ & $218(199)$ \\
Amyloidosis (25) & $1491(694)^{\star}$ & $349(173)^{\star}$ & $223(227)$ \\
Vasculitis (20) & $2016(842)$ & $505(285)$ & $208(96)$ \\
Membranous (7) & $1218(666)$ & $400(196)$ & $157(22)$ \\
Control (41) & $1870(622)$ & $399(188)$ & $167(82)$ \\
\hline
\end{tabular}

Values are mean (SD).

$\star P<0.05 v$ vasculitis.

Table 5 Comparison of class specific and conventional rheumatoid factors

\begin{tabular}{lccc}
\hline Group & $I g A-R F(n)$ & $I g M-R F(n)$ & $T I A-R F(n)$ \\
\hline IgA GN & $8 \cdot 6(9 \cdot 2,11)^{\star 1}$ & $8 \cdot 0(9 \cdot 4,11)^{\star 1}$ & $340(589,8)$ \\
Non-IgA GN & $2 \cdot 3(1 \cdot 8,6)^{\star \star 1}$ & $2 \cdot 7(2 \cdot 3,6)^{\star \star 1}$ & $60(39,9)^{\star \star 1}$ \\
Amyloidosis & $7 \cdot 1(6 \cdot 6,10)^{\star 1}$ & $7 \cdot 5(7 \cdot 8,10)^{\star 1}$ & $194(301,21)^{\star 1}$ \\
Vasculitis & $16 \cdot 6(11 \cdot 1,17)$ & $18 \cdot 6(13 \cdot 9,17)$ & $775(830,17)^{\star 1}$ \\
Membranous & $4 \cdot 6(3 \cdot 7,4)^{\star 1}$ & $4 \cdot 6(6 \cdot 1,4)^{\star 1}$ & $66(73,6)^{\star \star 1}$ \\
Control & $5 \cdot 1(4 \cdot 0,17)^{\star \star 1}$ & $5 \cdot 6(4 \cdot 8,17)^{\star \star 1}$ & $115(159,34)^{\star \star 1}$ \\
\hline
\end{tabular}

Values are mean $(\mathrm{SD})$

${ }^{\star} \mathrm{p}<0.05,{ }^{\star} \mathrm{p}<0.01 ; 1=v$ vasculitis, $2=v$ IgA GN amyloidosis group than in the group with vasculitis, the membranous group, or controls. Further, the mean stage of RA was significantly more advanced in patients with amyloidosis than in any other group (table 2).

Proteinuria was commonly found in patients with amyloidosis $(21 / 26 ; 81 \%)$ and the membranous group $(6 / 7 ; 86 \%)$, but the incidence of proteinuria was relatively low in patients with IgA GN $(5 / 13 ; 38 \%)$ or non-IgA GN (3/14; 21\%). Nephrotic syndrome was recognised more often in patients with membranous $(4 / 7 ; 57 \%)$ and amyloidosis $(7 / 26 ; 27 \%)$. Definite haematuria was, however, often seen in patients with IgA GN $(13 / 13 ; 100 \%)$ or non-IgA GN $(12 / 14 ; 86 \%)$, therefore isolated haematuria was prevalent in patients with RA and mesangiopathy. The incidence of haematuria in patients with amyloidosis was $50 \%(13 / 26)$. Renal dysfunction was often seen $(19 / 26 ; 73 \%)$ in patients with amyloidosis; however, renal dysfunction was infrequent in patients of other groups (table 3 ).

Table 4 shows serum immunoglobulin concentrations. Mean serum IgG and IgA concentrations were significantly higher in the vasculitis group than in the group with amyloidosis. The concentrations of IgG were also higher in the vasculitis group than in the non-IgA GN group. Mean serum IgA concentrations in patients with $\operatorname{IgA} \mathrm{GN}$ were comparable with those in other groups.

Table 5 shows the results of comparative studies of class specific and conventional RFs. Mean IgA-RF and IgM-RF concentrations were significantly higher in the vasculitis group than in any other group. The concentrations of TIA-RF were also significantly higher in the vasculitis group than in any other group except for the group with IgA GN. Also, mean IgARF concentrations were slightly higher in patients with IgA GN than in the non-IgA GN group.

\section{Discussion}

Renal failure has been thought to be one common cause of death in patients with RA, and histologically renal amyloidosis has been perceived as a main cause of renal failure in several studies. ${ }^{30} 31$ Prolonged inflammation accompanied by chronic polyarthritis has been considered to be responsible for the occurrence and progression of secondary amyloidosis in patients with RA. ${ }^{32}$ 33 The present study confirmed the concept that patients with longstanding and advanced RA may be prone to secondary amyloidosis, and that secondary amyloidosis may be the major cause of renal failure in these patients, whereas the low IgG concentrations in this group were considered to be connected to the high frequency of profuse proteinuria.

Membranous nephropathy has also been described as a major complication in patients with RA, usually associated with the use of antirheumatic drugs such as gold or D-penacillamine. ${ }^{568}$ In our study, antirheumatic drugs were recognised as re- 
sponsible for the occurrence of $M N$ in four out of seven patients, although three other patients received no antirheumatic drug when their renal disorder developed. There have been several cases of $M N$ in patients with $R A$ not treated with antirheumatic drugs. ${ }^{34}$ Further, Samuels $e t a l^{35}$ assumed that the nephropathy may be linked pathogenetically to the RA. Further studies are needed to resolve these problems.

Glomerulonephritis had been considered, until about 20 years ago, to be a rare complication of RA. ${ }^{14} 3637$ In recent renal biopsy electron and immunofluorescence microscopy studies, mild mesangial proliferative $\mathrm{GN}$ has been shown to be a common finding in patients with RA presenting with haematuria or proteinuria. ${ }^{315-18}$ Our study of renal biopsy specimens by light microscopy showed also that an increase in mesangial matrix or mesangial cells was a common histological abnormality in patients with RA, and that most of these patients presented with haematuria dominant urinary abnormalities. There is little evidence regarding NSAID induced mesangial glomerulopathy, ${ }^{9}{ }^{10}$ and a relation between exposure to antirheumatic drugs and haematuria has not been well established..$^{18-41}$ Therefore, it is plausible that these urinary findings are associated with mesangial glomerulopathy itself. ${ }^{3}$

Recent immunopathological analyses of renal disorders in patients with $R A$ have yielded somewhat conflicting results. For example, Korpela et al ${ }^{18}$ found that the most common immunofluorescence finding in mesangial GN associated with $R A$ was mesangial IgM deposition, even though in many cases of mesangiopathy, no deposition was seen. ${ }^{42}$ More recently, patients with RA complicated by IgA GN have been reported sporadically, ${ }^{23} 4344$ and IgA GN was often found in our study of Japanese patients with RA.

Systemic rheumatoid vasculitis with extraarticular lesions has been related to high titres of $\mathrm{RF}$ in several studies. ${ }^{45}{ }^{46} \mathrm{~A}$ similar positive correlation between RFs and extra-articular features was noted in the present study. Moreover, RFs have been assumed to have a pathogenetic role in the development of some types of GN, ${ }^{21} 22{ }^{47-50}$ whereas, Korpela et $a l^{23}$ reported that RFs may not have any role in the pathogenesis of various nephropathies in patients with RA. Also, protective roles for RF have been suggested by several studies. ${ }^{51-53}$ To clarify the pathogenesis of IgA GN in patients with RA, we examined class specific RFs, including IgA-RF. There was little correlation between histopathological injury to kidney tissue and the serum concentration of any class of RF, although the mean IgA-RF concentration was slightly higher in patients wth IgA GN than in the group with non-IgA GN.

Certain genetic or geographic factors have also been related to the onset of primary $\operatorname{IgA}$ GN. Fauchet $e t a l^{54}$ found a significant association of HLA-DR4 with primary IgA GN $(48.8 \%$ in 45 patients with IgA GN versus $19.5 \%$ in the controls). A similar finding in
Japanese patients was reported by Hiki et al..$^{55}$ HLA-DR4 antigen is also thought to be related to the occurrence and progression of RA in several countries. ${ }^{5657}$ Therefore, a common pathogenetic basis may exist that explains the concurrence of RA and IgA GN. However, because IgA $\mathrm{GN}$ is the most common primary glomerular disease in the Japanese population, ${ }^{55} 58$ the prevalence of $\operatorname{IgA}$ GN in Japanese patients with RA in our study may be related to the high frequency of IgA GN in the Japanese population. This may explain why Korpela et $a l^{23}$ reported that the frequency of IgA GN in patients with RA was nearly equal to that seen in the general population.

In the present study, renal function was maintained in every patient with mesangiopathy except for one patient with IgA GN. Although primary IgA GN was thought to take a benign course, some cases did progress to end stage renal failure after 10 to 20 years. ${ }^{59}$ From their longitudinal study of patients with RA, Korpela et al also showed that one out of three cases with IgA GN developed end stage renal failure. ${ }^{18}$ Therefore, the clinical course of IgA GN in patients with RA may be similar to that of primary IgA GN.

In conclusion, renal histological evaluation showed that mesangial proliferative $\mathrm{GN}$ with mesangial IgA deposits was the most common type of nephropathy in Japanese patients with RA. Little correlation was found between mesangial glomerulopathy and the serum concentration of any class of RF. Further study should aim to clarify the role of IgA RF in the development of IgA GN in patients with RA. Although renal dysfunction was infrequent in our patients with RA and mesangial glomerulopathy, careful prospective studies may be necessary for such patients because the natural course and importance of the disease combination are not fully understood.

1 Browning $M$ J, Banks R A, Tribe C R, et al. Ten years' experience of an amyloid clinic - a clinicopathological experience of an amyloid clinic - a
survey. $O f M e d ~ 1985 ; 215: 213-27$.

2 Husby G. Amyloidosis and rheumatoid arthritis. Clin Exp Rheumatol 1985; 3: 173-80.

3 Helin H J, Korpela M M, Mustonen J T, Pasternack A I Renal biopsy findings and clinicopathologic correlations in theumatoid arthritis. Arthritis Rheum 1995; 38: 242-7.

Sellars L, Siamopoulos K, Wilkinson R, Leohapand T Morley A R. Renal biopsy appearances in rheumatoid disease. Clin Nephrol 1983; 20: 114-20.

5 Hall C L, Fothergill N J, Blackwell M M, Harrison P R, MacKenzie J C, MacIver A G. The natural course of gold nephropathy: long term study of 21 patients. $B M \mathcal{F} 1987$; 295: 745-8.

6 Hall C L. Gold nephropathy. Nephron 1988; 50: 265-72.

7 Howard-Lock H E, Lock C J L, Mewa A, Kean W F. D-Penicillamine: chemistry and clinical use in rheumatic D-Penicillamine: chemistry and clinical use in rhe

8 Hall C L, Jawad S, Harrison P R, et al. Natural course of penicillamine nephropathy: a long term study of 33 patients. $B M F$ 1988; 296: 1083-6.

9 Garella S, Matarese RA. Renal effects of prostaglandins and clinical adverse effects of nonsteroidal anti-inflammatory agents . Medicine 1984; 63: 165-81.

10 Kleinknecht D, Landais P, Goldfarb B. Analgesic and nonsteroidal anti-inflammatory drug-associated acute renal failure: a prospective collaborative study. Clin Nephrol 1986; 25: 275-81.

11 Sandler D P, Burr F R, Weinberg C R. Nonsteroidal antiinflammatory drugs and the risk for chronic renal disease. Ann Intern Med 1991; 115: 165-72.

12 Shankel S W, Johnson D C, Clark P S, Shankel T L, O'Neil W M. Acute renal failure and glomerulopathy caused by nonsteroidal anti-inflammatory drugs. Arch Intern Med nonsteroidal anti-in

13 Perneger T V, Whelton P K, Klag M J. Risk of kidney failure associated with the use of acetaminophen, aspirin, and nonsteroidal antiinflammatory drugs. $N$ Engl $f$ Med 1994
331: 1675-9. 
14 Davis J A, Cohen A H, Weisbart R, Paulus H E. Glomerulonephritis in rheumatoid arthritis. Arthritis Rheum 1979; 22: 1018-23.

15 Hordon L D, Sellars L, Morley A R, Wilkinson R, Thompson M, Griffiths I D. Haematuria in rheumatoid arthritis: an association with mesangial glomerulonephritis. Ann Rheum Dis 1984; 43: 440-3.

16 Boers M. Renal disorders in rheumatoid arthritis. Semin Arthritis Rheum 1990; 20: 57-68.

17 Helin H, Korpela M, Mustonen J, Pasternack A. Mild mesangial glomerulopathy - a frequent finding in
rheumatoid arthritis patients with hematuria or rheumatoid arthritis patients with
proteinuria. Nephron 1986; 42: 224-30.

18 Korpela M, Mustonen J, Pasternack A, Helin H. Mesangial glomerulopathy in rheumatoid arthritis patients. Nephron 1991; 59: 46-50.

19 McIntosh R M, Garcia R, Rubio L, et al. Evidence for an autologous immune complex pathogenic mechanism in acute poststreptococcal glomerulonephritis. Kidney Int 1978; 14: 501-10.

20 Endoh $M$, Suga T, Sakai H. IgG, IgA and IgM rheumatoid factors in patients with glomerulonephritis. Nephron 1985; 39: $330-5$

21 Sinico R A, Fornasieri A, D'Amico G. Role and clinical significance of rheumatoid factors in glomerulonephritis. Contrib Nephrol 1988; 61: 149-55.

22 Pollett S, Depner T, Moore P, Olander H, Robbins D. Mesangial glomerulopathy and IgM rheumatoid factor in Mesangial glomerulopathy and IgM rheumatoid
rheumatoid arthritis. Nephron 1989; 51: 107-11.

23 Korpela M, Mustonen J, Helin H, Pasternack A Immunological comparison of patients with rheumatoid arthritis with and without nephropathy. Ann Rheum Dis 1990; 49: 214-8

24 Arnett F C, Edworthy S M, Bloch D A, et al. The American Rheumatism Association 1987 revised criteria for the classification of rheumatoid arthritis. Arthritis Rheum 1988; 31: 315-24.

25 Steinbrocker O, Traeger C H, Batterman R C. Therapeutic criteria in rheumatoid arthritis. $\mathcal{F A M A} 1949 ; 140$ : 659-62.

26 Bampton J L M, Cawston T E, Kyle M V, Hazleman B L. Measurement of rheumatoid factors by enzyme-linked Measurement of rheumatoid factors by enzyme-linked immunosorbent assay (ELISA) and compariso

27 Powell R J, Leyland A M, Pound J D, Bossingham D H. An improved assay for IgG rheumatoid factors: its value in the diagnosis of rheumatoid arthritis. $\mathcal{F}$ Rheumatol 1985; 12: 427-31.

28 Gioud-Paquet $M$, Auvinet $M$, Raffin $T$, et al. IgM rheumatoid factor (RF), IgA RF, IgE RF, and IgG RF detected by ELISA in rheumatoid arthritis. Ann Rheum Dis 1987; 46: 65-71.

29 McCoy R C, Abramowsky C R, Tisher C C. IgA nephropathy. Am 7 Pathol 1974; 76: 123-44.

30 Laakso M, Mutru O, Isomäki H, Koota K. Mortality from amyloidosis and renal diseases in patients with rheumatoid arthritis. Ann Rheum Dis 1986; 45: 663-7.

31 Mutru O, Laakso M, Isomäki $H$, Koota $K$. Ten year mortality and causes of death in patients with rheumatoid mortality and causes of death in patie

32 Falck H M, Maury C P, Teppo A M, Wegelius $O$. Correlation of persistently high serum amyloid A protein and C-reactive protein concentrations with rapid progression of secondary amyloidosis. $B M Y 1983 ; 286$ 1391-3.

33 Gertz M A, Kyle R A. Secondary systemic amyloidosis: response and survival in 64 patients. Medicine 1991; 70: 246-56.

34 Honkanen E, Törnroth T, Pettersson E, Skrifvars B. Membranous glomerulonephritis in rheumatoid arthritis not related to gold or D-penicillamine therapy: a report not related to gold or D-penicilamine therapy: a report
of four cases and review of the literature. Clin Nephrol of four cases and

35 Samuels B, Lee J C, Engleman E P, Hopper Jr J. Membranous nephropathy in patients with rheumatoid arthritis: relationship to gold therapy. Medicine 1997; 57 319-27.

36 Ramirez G, Lambert R, Bloomer H A. Renal pathology in patients with rheumatoid arthritis. Nephron 1981; 29: $124-6$.
37 Pasternack A, Wegelius D, Makisara P. Renal biopsy in rheumatoid arthritis. Acta Med Scand 1967; 182: $591-5$

38 White E G, Smith D H, Zaphiropoulos G C. Haematuria occurring during antirheumatoid therapy. Br $\mathcal{F}$ Rheumatol 1984; 23: 57-60.

39 Leonard P A, Bienz S R, Clegg D O, Ward J R. Hematuria in patients with rheumatoid arthritis receiving gold and D-Penicillamine. $\mathcal{F}$ Rheumatol 1987; 14: 55-9.

40 Kelly C A, Mooney P, Hordon L D, Griffiths I D. Haematuria in theumatoid arthritis: a follow up study. Ann Rheum Dis 1988; 47: 993-4.

41 Saito $T$, Nishi $S$, Karasawa $R$, In Hayashi $H$, Ueno $M$, Ogino $\mathrm{S}$, et al. An ultrastructural study of glomerular basement membrane in rheumatoid arthritis patients with urinary abnormalities. Clin Nephrol 1995; 43: with ur 7 .

42 Salomon M I, Gallo G, Poon T P, Goldblat MV, Tchertkoff $\mathrm{V}$. The kidney in RA, a study based on renal biopsies. Nephron 1974; 12: 297-310.

43 Beaman M, Adu D, Howie A J, McConkey B, Michael J, Popert A J. Rheumatoid arthritis and IgA nephropathy. Br $\mathcal{F}$ Rheumatol 1987; 26: 299-302.

44 Sato M, Kokima H, Koshikawa S. IgA Nephropathy in rheumatoid arthritis. Nephron 1988; 48: 169-70.

45 Scott D G I, Bacon P A, Tribe C R. Systemic rheumatoid vasculitis: a clinical and laboratory study of 50 cases. Medicine 1981; 60: 288-97.

46 Wesedt M L, Herbrink P, Molenaar J L, et al. Rheumatoid factors in rheumatoid arthritis and vasculitis. Rheumatol Int 1985; 5: 209-14.

47 Czerkinsky C, Koopman W J, Jackson S, et al. Circulating immune complexes and immunoglobulin $\mathrm{A}$ rheumatoid factor in patients with mesangial immunoglobulin A nephropathies. F Clin Invest 1986; 77: 1931-8.

48 Sesso R C C, Ramos O L, Pereira A B. Detection of IgGrheumatoid factor in sera of patients with acute poststreptococcal glomerulonephritis and its relationship with circulating immune complexes. Clin Nephrol 1986; 26: $55-60$.

49 Sinico $R$ A, Fornasieri A, Maldifassi P Colasanti G, D'Amico G. The clinical significance of IgA rheumatoid factor in idiopathic IgA mesangial nephropathy (Berger's factor in idiopathic IgA mesangial neph

50 Miyazaki M, Endoh M, Suga T, et al. Rheumatoid factors and glomerulonephritis. Clin Exp Immunol 1990; 81: $250-5$

51 Hill G S, Hinglain N, Tron F, Bach J-F. Systemic lupus erythematosus: morphologic correlations with immunologic and clinical data at the time of biopsy. $A m \mathcal{F} M e d$ 1978; 64: 61-79.

52 Bolton W K, Schrock J H, Davis IV J S. Rheumatoid factor inhibition of in vitro binding of IgG complexes in the hum

53 Helin H, Korpela M, Mustonen J, Pasternack A. Rheumatoid factor in rheumatoid arthritis associated renal disease and in lupus nephritis. Ann Rheum Dis 1986; 45: 508-11.

54 Fauchet R, Le Pogamp P, Genetet B, et al. HLA-DR4 antigen and IgA nephropathy. Tissue Antigens 1980; 16: 405-10.

55 Hiki Y, Kobayashi Y, Tateno S, Sada M, Kashiwagi N. Strong association of HLA-DR4 with benign IgA nephropathy. Nephron 1982; 32: 222-6.

56 van Zeben $\mathrm{D}$, Hazes J $\mathrm{M}$, Zwinderman $\mathrm{A} \mathrm{H}$, et al. Association of HLA-DR4 with a more progressive disease course in patients with rheumatoid arthritis. Results of a follow up study. Arthritis Rheum 1991; 34: 822-30.

57 Doita M, Hirohata K, Maeda S. Association of HLA-DR antigens with disease severity in Japanese patients
with rheumatoid arthritis. Kobe $\mathcal{f}$ Med Sci 1990; 36: with rhe $103-14$.

58 Ueda Y, Sakai O, Yamagata M. Kitajima T, Kawamura K. IgA glomerulonephritis in Japan. Contrib Nephrol 1977; 4: $36-47$

59 Mustonen J, Pasternack A, Helin H, Nikkilä $M$. Clinicopathologic correlations in a series of 143 patients with IgA glomerulonephritis. Am $\mathcal{f}$ Nephrol 1985; 5: 150-7. 